\title{
Hepatocellular carcinoma complicating chronic granulomatous hepatitis
}

\author{
WM MELIA, H CALVEY, B PORTMANN, ROGER WILLIAMS \\ From the Liver Unit, King's College Hospital and Medical School, Denmark Hill, London SE5
}

SUMMARY The development of hepatocellular carcinoma, is reported in a patient with chronic granulomatous hepatitis after a seven year interval in which clinical and biochemical improvement had occurred on corticosteroid therapy and in whom, the development of cirrhosis was excluded by liver biopsy.

Hepatocellular carcinoma is a well recognised complication of cirrhosis, particularly those types that occur in males and in association with hepatitis B virus infection. ${ }^{1}$ It has also been seen very rarely in long-standing cases of hepatic fibrosis consequent on various chronic liver disorders-for example, HBsAg positive chronic active hepatitis, in -which cirrhosis is more usually found. ${ }^{2}$ To our knowledge, however, there have been no previous reports of tumour development in chronic granulomatous hepatitis. We describe here a patient in whom hepatocellular carcinoma occurred seven years after the diagnosis of this condition and in whom serial liver biopsies over the years have shown little progression of the lesion and no development of cirrhosis.

\section{Case report}

A 48-year-old man was admitted to the Royal Infirmary, Doncaster in December 1973 following an episode of haematemesis and melaena. Clinical examination revealed hepatosplenomegaly, and oesophageal varices were demonstrated on barium swallow. Subsequently he was transferred to the Liver Unit where a history of gradually increasing abdominal distension during the previous year was obtained. On abdominal examination, the spleen was palpable $16 \mathrm{~cm}$ below the left costal margin, the liver edge $6 \mathrm{~cm}$ below the xiphisternum, and there was some ascites.

Laboratory investigations were as follows (Fig. 1): Erythrocyte sedimentation rate (ESR) $4 \mathrm{~mm} / \mathrm{h}$; haemoglobin concentration $11.6 \mathrm{~g} / \mathrm{dl}$; white cell count $3.7 \times 10^{9} / 1$ with a normal differential

Accepted for publication 21 April 1983 count; serum bilirubin $24 \mu \mathrm{mol} / \mathrm{l}$; alkaline phosphatase (ALP) $96 \mathrm{IU} / \mathrm{l}$; aspartate aminotransferase (AST) $33 \mathrm{IU} / \mathrm{l}$; serum calcium $2.40 \mathrm{mmol} / \mathrm{l}$ and other electrolytes normal. The prothrombin time was six seconds prolonged.

Serum was negative for HBsAg (RIA, Travenol Laboratories Ltd) and anti-HBs (Ausab, Abbott Laboratories) and alpha fetoprotein (AFP) was in the normal range (RIA, Radiochemicals Ltd) Autoantibody screening was negative apart frore positive antinuclear factor in a titre of $1 / 20$.

A radionuclide liver scan ( ${ }^{99} \mathrm{MTechnetium} \mathrm{sulph}$ colloid) showed that isotope uptake by the liver was reduced and that the right lobe had decreased in size. The spleen was markedly enlarged with an uptake of isotope greater than the liver. Mantoux and Kveim tests were negative; chest $x$-ray and slit lamp examination of the eyes were normal. Splenic venography showed an intrasplenic pressure of $32 \mathrm{~mm} \mathrm{Hg}$ with patent splenic and portal veins.

Splenectomy with an end-to-side lienorenal shunt was performed on 6 March 1974, after which the oesophageal varices, assessed radiologically, became smaller. Histological examination of the spleen $\delta$ revealed multiple granulomata as well as congestive changes and a liver biopsy performed at that time 0 showed widespread granuloma formation. After discharge from hospital he was able to recommence $\frac{}{2}$ work and remained well until March 1975 when serum AST was found to have risen to $770 \mathrm{IU} / 1$, the of ALP to $333 \mathrm{IU} / \mathrm{l}$ and bilirubin to $23 \mu \mathrm{mol} / \mathrm{l}$. After $N$ treatment with prednisolone ( $10 \mathrm{mg}$ daily) there was N a steady improvement in liver function tests, and by October, serum AST had fallen to 29 IU/l, ALP $67 \mathrm{IU} / \mathrm{l}$ and bilirubin to $12 \mu \mathrm{mol} / \mathrm{l}$. Over the next two years he remained well and the liver became $\stackrel{\Phi}{?}$ impalpable. From October 1977, prednisolone was gradually withdrawn and stopped altogether in June 1062 


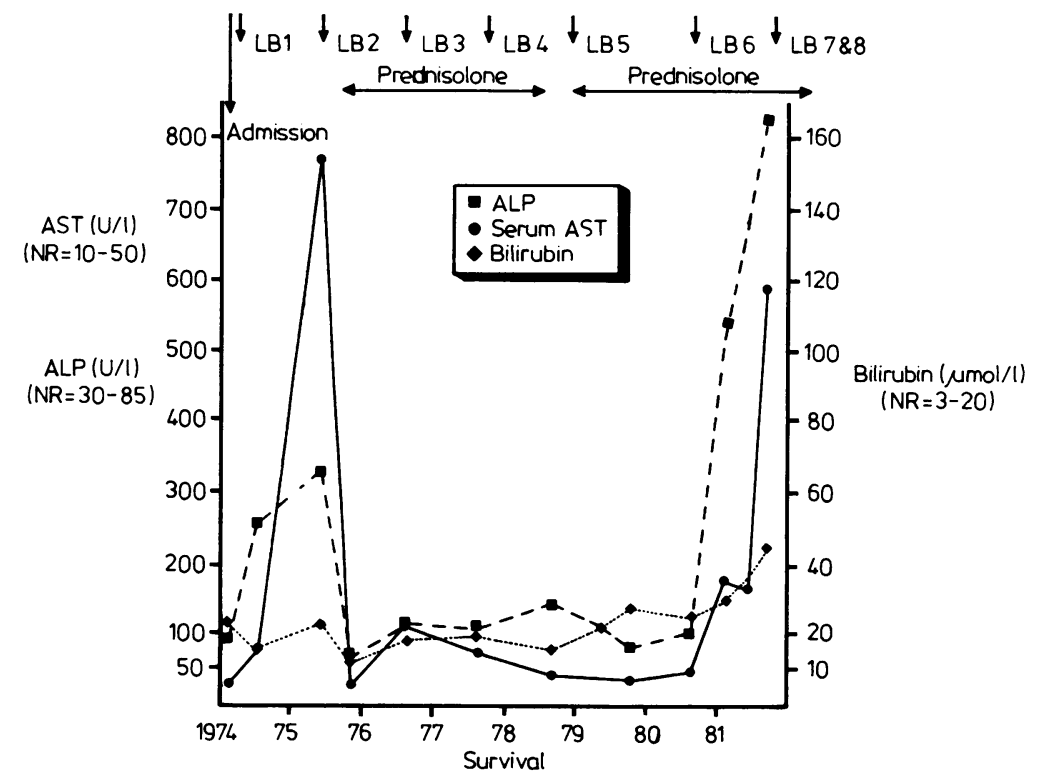

Fig. 1 Serum aspartate aminotransferase (AST) and alkaline phosphatase (ALP) activities and bilirubin concentrations in a 48-year-old man with granulomatous hepatitis first diagnosed in January 1974, who developed hepatocellular carcinoma in August 1981 ( $L B=$ liver biopsy).

1978. However, a further liver biopsy in December revealed more florid changes and prednisolone (10 mg daily) was restarted. When he developed mild exertional dyspnoea in February 1979 the dosage was increased to $15 \mathrm{mg}$ daily.

In February 1981 he complained that he became easily fatigued, and on examination was noticed to be jaundiced. The liver edge was palpable $6 \mathrm{~cm}$ below the right costal margin. Liver function tests showed a serum AST of $176 \mathrm{IU} / 1$, ALP $517 \mathrm{IU} / 1$ and bilirubin $30 \mu \mathrm{mol} / \mathrm{l}$. The dosage of prednisolone was increased to $20 \mathrm{mg}$ daily, but he continued to lose weight and complained of abdominal discomfort, together with increased breathlessness on exertion. In August the liver had enlarged further $(10 \mathrm{~cm}$ below the costal margin) and liver function tests showed deterioration with a serum AST of 590 IU/, ALP $825 \mathrm{IU} / 1$ and bilirubin $44 \mu \mathrm{mol} / \mathrm{l}$. Serum AFP was slightly raised at $35 \mathrm{ng} / \mathrm{ml}$ (normal range 0 $10 \mathrm{ng} / \mathrm{ml}$ ) and liver ultrasound revealed multifocal solid filling defects in the right lobe. Percutaneous liver biopsy from this area confirmed hepatocellular carcinoma. Investigations into the cause of his breathlessness included a chest $x$-ray which revealed a metastasis in the right lower lobe. Lung function tests showed a vital capacity of 3.41 (predicted value 4.61 ), one-second forced expiratory volume of 2.61 (predicted $3.4 \mathrm{l}$ ), CO transfer factor $22.4 \mathrm{mmol} /$ $\mathrm{kPa} / \mathrm{min}$ (predicted $30 \mathrm{mmol} / \mathrm{kPa} / \mathrm{min}$ ) and permeability constant $3.8 / \mathrm{min}$ (predicted $4.4 / \mathrm{min}$ ), changes indicative of a transfer defect.

Chemotherapy with adriamycin was commenced but serum AFP concentrations continued to rise and there was an increase in tumour size on serial ultrasound examinations. There was a gradual deterioration and he died at home in April 1982.

\section{SERIAL LIVER HISTOLOGY}

Eight needle liver biopsies obtained at approximately yearly intervals since 1974 were available for review.

The initial biopsy showed the portal tracts to be expanded due to fibrous tissue deposition with conspicuous mixed cell infiltrates and discrete nonnecrotising granuloma formation. A mild and patchy lobular inflammation was also observed. Similar changes were seen on the 1975 specimen, except that the granulomata were more numerous, in places confluent, and the portal cell infiltrate denser and often aggressive towards the nearby limiting plates (Fig. 2). There was a substantial improvement in this activity on the 1976 specimen (Fig. 3) when the patient had been on a daily dose of $10 \mathrm{mg}$ of prednisolone for one year, and the 1977 biopsy showed 


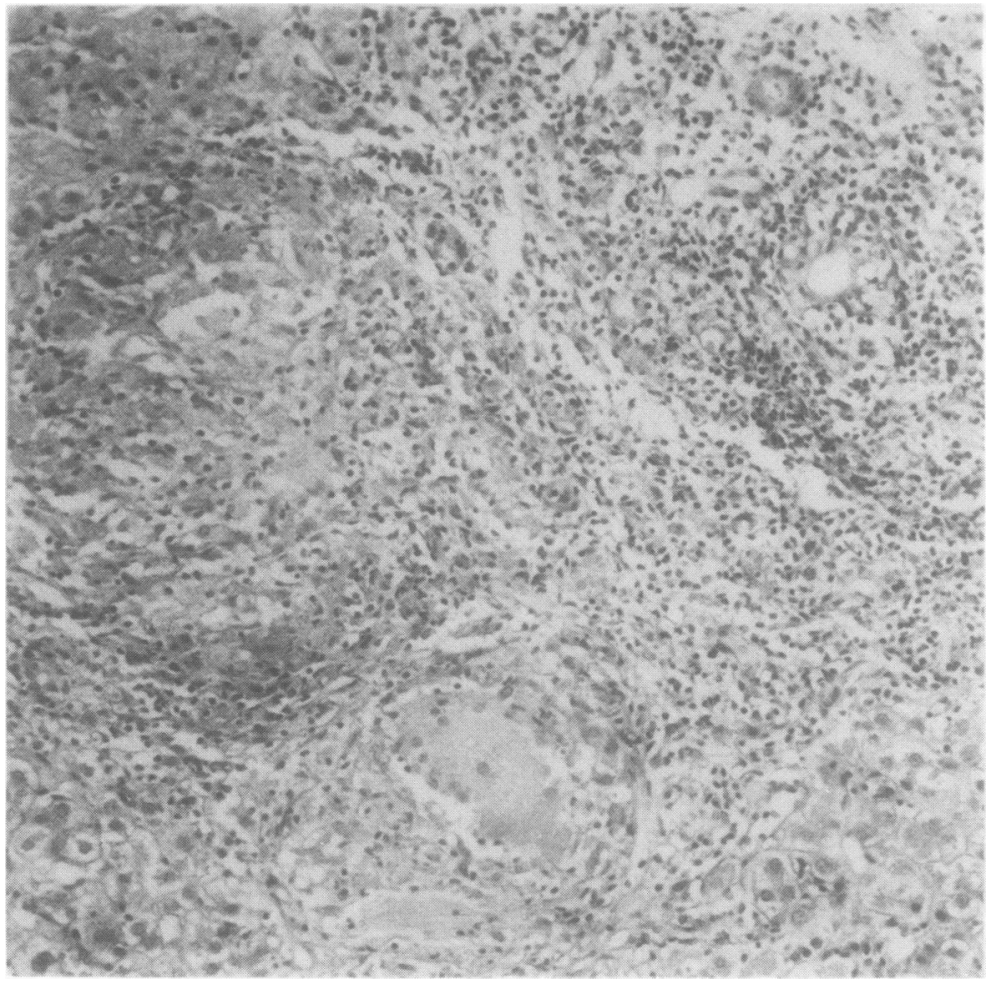

Fig. 2 Florid giant cell granulomata in and around $a$ markedly enlarged portal area. Haematoxylin and eosin $\times 100$.

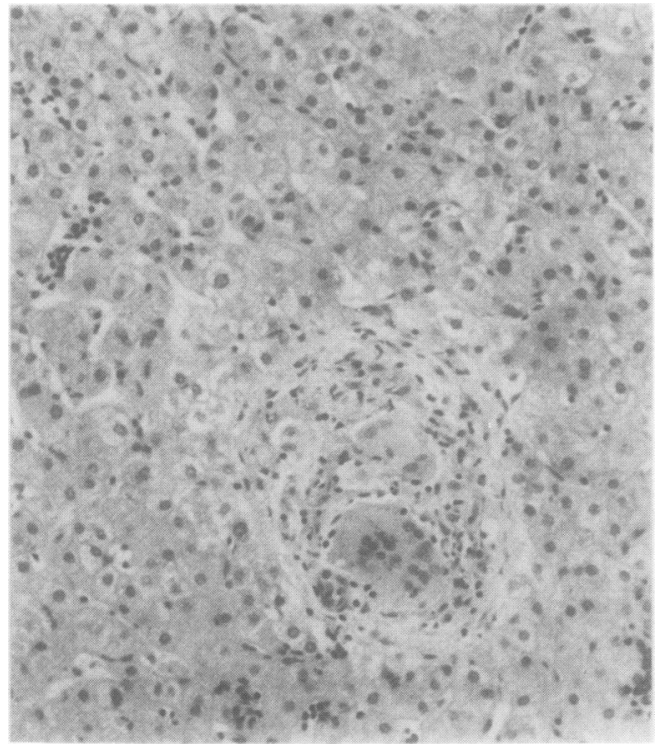

Fig. 3 Mild residual inflammation with one granuloma and a well-preserved lobular architecture. Haematoxylin and eosin $\times 100$. the features of chronic persistent hepatitis with mild residual lobular inflammation and was the only $\stackrel{\square}{\square}$ non-tumoral specimen devoid of granulomatous $\overrightarrow{\vec{F}}$ infiltration. A further biopsy performed after steroid $\frac{\circ}{3}$ withdrawal in 1978 revealed florid portal and periportal activity identical to that seen on the 1975 훙 sample. In July 1980, a year after steroid treatment had been resumed, activity was again markedly? reduced, although giant cell granulomata were still present within slightly expanded portal tracts. Over the years there had been no significant increase in 0 extent or degree of fibrosis, which was moderate on all specimens. The lobular pattern was well pre- 음 served in five and slightly distorted in one (1975). $\rightarrow$ None of the biopsies showed evidence of nodular regeneration. The Ziehl Nielsen method for acid- N fast bacilli, Grocott's method for fungi, and periodic ${ }^{\circ}$ acid-Schiff reaction after diastase treatment did not 0 reveal any aetiological agent in the six biopsy speci- $\omega$ mens with granulomata. The biopsy performed in August 1981 revealed a very different picture, witho a severely collapsed liver architecture and a mixed $\overparen{\varnothing}$ pattern of venous outflow block and cholangitis, $\stackrel{?}{+}$ strongly suggestive of compression of the liver by an $\underline{T}$ expanding process. A repeat biopsy under $\frac{\vec{\Phi}}{\mathbb{D}}$ 


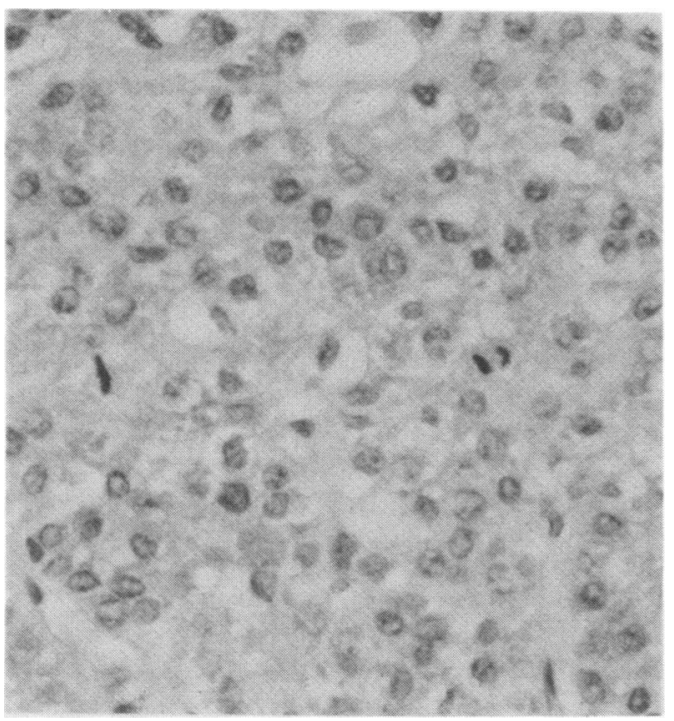

Fig. 4 Hepatocellular carcinoma with relatively compact growth of clear cells of which two are in mitosis. Haematoxylin and eosin $\times 180$.

ultrasound direction two weeks later confirmed the presence of a moderately differentiated hepatocellular carcinoma (Fig. 4).

\section{Discussion}

The most likely cause of the granulomatous hepatitis in this patient was sarcoidosis. Although a Kveim test was negative and there was no radiological evidence of pulmonary involvement, epithelioid granulomata were demonstrated in both liver and spleen tissue, and dyspnoea had been present for over two years before lung function tests, compatible with fibrosing alveolitis, were demonstrated.

The definite clinical and biochemical response to corticosteriods is also consistent with hepatic sarcoidosis. ${ }^{3}$ Indeed, the Kveim test is often negative in patients with hepatic sarcoidosis. In a review of 30 patients with granulomatous hepatitis, Israel and Goldstein ${ }^{4}$ describe nine with definite, and another seven with probable, sarcoidosis of whom only two had positive Kveim tests. Similarly, in six of 13 patients with hepatic sarcoidosis described by Maddrey $^{3}$ the Kveim test was negative.

Progression of granulomatous hepatitis to cirrhosis has been reported in occasional cases, ${ }^{5-8}$ but in the present patient the eight serial liver biopsies obtained over a seven-year period showed no such evidence. The portal hypertension was due to extensive granulomata and fibrosis in the portal tracts and is described in hepatic granulomatosis in the absence of cirrhosis. ${ }^{9} 3$

The development of hepatocellular carcinoma in such a patient in the absence of cirrhosis is thus of considerable interest. An increased incidence of neoplasia (malignant lymphoma and lung cancer) has been reported by Brincker and Wilder ${ }^{10}$ in patients with respiratory sarcoidosis although this has not been confirmed, and there is one report of malignancy at another site (malignant melanoma) in a patient with long-standing granulomatous hepatitis. ${ }^{4}$ However, we have been unable to find any previous report of hepatocellular carcinoma either in respiratory or other clinical variants of sarcoidosis; or in chronic granulomatous hepatitis from other causes. Other factors to be considered in relation to the development of malignancy in this patient are splenectomy and the prolonged use of corticosteroids. Robinette and Fraumeni ${ }^{11}$ did not find an increased incidence of malignancy in World War II veterans who had undergone splenectomy following trauma.

The present patient was on prednisolone therapy for six years and a convincing relation has been established between immunosuppressive drug therapy and an increased incidence of malignant tumours in patients after organ transplantation. ${ }^{12}$ Although the tumours which are found are most frequently mesenchymal (lymphoma) or epithelial (particularly carcinomas of skin, lip and uterine cervix) origin, there is one reported case of hepatocellular carcinoma developing in a child after renal transplantation. ${ }^{13}$ There is also some suggestion that cancers occur in non-transplant patients being treated with corticosteroids ${ }^{14}{ }^{15}$ and the question of whether patients with autoimmune liver disease on immunosuppressive drugs have an increased risk of hepatocellular carcinoma, has been raised by several workers. ${ }^{16}{ }^{17}$ However, with the exception of carcinoma of the skin, the results of the Oxford collaborative study performed between 1970 and 1978 failed to provide any clear evidence of an increased risk of the more common cancers in non-transplant patients treated with immunosuppressive drugs. ${ }^{18}$

\section{References}

' Johnson PJ, Krasner N, Portmann B, Eddleston ALWF, Williams R. Hepatocellular carcinoma in Great Britain. Influence of age, sex, HBsAg status and aetiology of underlying cirrhosis. Gut 1978;19:1022-6.

${ }^{2}$ Shikata T. Primary liver carcinoma and liver cirrhosis. In: Okuda K, Peters RL, eds. Hepatocellular carcinoma. New York: John Wiley and Sons, 1976:53-71.

${ }^{3}$ Maddrey WC, Jones CJ, Boitnott JK, Iber FL. Sarcoidosis and chronic hepatic disease: a clinical and pathological study of 20 patients. Medicine (Baltimore) 1970;49:375-95.

4 Israel HL, Goldstein RA. Hepatic granulomatosis and sarcoidosis. Ann Intern Med 1973;79:669-78. 
${ }^{5}$ Bunim JJ, Kimberg DV, Thomas LB, Van Scott J, Klatskin G. The syndrome of sarcoidosis, psoriasis and gout. Combined clinical staff conference at the National Institutes of Health. Ann Intern Med 1962;57:1018-40.

- Branson JH, Park JH. Sarcoidosis: hepatic involvement. Ann Intern Med 1954;40:111-45.

' Kelley ML, McHardy RJ. An unusual case of fatal hepatic sarcoidosis. Am J Med 1955;18:842-50.

${ }^{8}$ Schiff L. Needle biopsy studies of the liver in cirrhosis and other conditions. In: Liver disease. Ciba Found Symp 1951;p 101.

' Porter GH. Hepatic sarcoidosis-a cause of portal hypertension and liver failure: a review. Arch Intern Med 1961;106:483-95.

${ }^{10}$ Brincker $\mathrm{H}$, Wilder $\mathrm{E}$. The incidence of malignant tumours in patients with respiratory sarcoidosis. $\mathrm{Br} J$ Cancer 1974;29:247-51.

" Robinette CD, Fraumeni JF Jr. Splenectomy and subsequent mortality in veterans of the 1939-1945 war. Lancet 1977;ii:127-9.

${ }_{12}^{2}$ Penn I. Chemical immunosuppression and human cancer. Cancer 1974;34:1474-80.

${ }^{13}$ Arbus GS, Hung RH. Hepatocarcinoma and myocardial fibrosis in an 83/4-year-old renal transplant recipient. J Can Med Assoc 1972;107:431-2.

${ }^{14}$ Nabarro JDN. The pituitary and adrenal cortex in general medicine. Br Med J 1960;ii:625-33.

${ }^{15}$ Kelly M. Corticosteroids and carcinogenesis-further suggestive evidence. Acta Rheum Scand 1961;7:315-20.

${ }^{16}$ Viteri A, Vernace SJ, Schaffner F. Extrahepatic malignancy in chronic liver disease: report of six cases. Gastroenterology 1976;71:1075-8.

${ }^{17}$ Chaput JC, Buffet C, Papoz L, Etienne JP. Chronic active hepatitis and extrahepatic malignancy. Lancet 1978;i:1367.

${ }^{18}$ Kinlen LJ, Sheil AGR, Peto J, Doll R. Collaborative United Kingdom-Australasian study of cancer in patients treated with immunosuppressive drugs. Br Med J 1979;ii:1461-6.

Requests for reprints to: Dr R Williams, The Liver Unit, King's College Hospital and Medical School, Denmark Hill, London SE5 8RX, England. 